\title{
Analisis Video Comments to Video Like akun Tiktok Brand Fashion Termahal di Dunia dengan Follower Terbanyak
}

\author{
I Made Arya Wijaksana \\ aryakadek012@gmail.com
}

\begin{abstract}
Information and Communication Technology is currently growing rapidly so that it can make it easier for everyone to exchange information with others through social media. One of the social media that currently has a big influence is Tiktok. Tiktok is a social media that is used as a place to spread and share information, interact with people, and get to know each other more closely. The large number of active Tiktok users in Indonesia can certainly provide an opportunity for brands to make the Tiktok platform a social media marketing platform. This study aims to find the ratios found on Tiktok social media. The research method used is exploratory to find the variables contained in Tiktok. The results of this Tiktok social media research show that the Ralph Lauren distribution brand is ranked first and has good account performance credibility.
\end{abstract}

\begin{abstract}
ABSTRAK
Teknologi Informasi dan Komunikasi saat ini telah berkembang pesat sehingga mampu memudahkan setiap orang untuk bertukar informasi dengan orang lain melalui sosial media. Sosial media yang yang saat ini memiliki pengaruh besar salah satunya yaitu Tiktok. Tiktok adalah media sosial yang digunakan sebagai tempat menyebarkan dan berbagai informasi, berinteraksi dengan orang banyak, serta dapat mengenal lebih dekat dengan sesama pengguna. Maraknya jumlah pengguna Tiktok yang aktif di Indonesia tentu dapat memberikan peluang bagi brand untuk menjadikan platform Tiktok sebagai platform social media marketing. Penelitian ini bertujuan untuk menemukan rasio - rasio yang terdapat pada sosial media Tiktok. Metode penelitian yang digunakan yaitu ekploratif untuk menemukan variabel - variabel yang terdapat pada Tiktok. Hasil dari penelitian sosial media Tiktok ini menunjukan bahwa brand Ralph Lauren mendapatkan peringkat pertama dan memiliki kredibilitas performa akun yang baik.
\end{abstract}

Keywords : Social Media, Tiktok, Tiktok Ratio, Credibility of Accounts Tiktok. 


\section{PENDAHULUAN}

Media Sosial memiliki berbagai manfaat untuk manusia di era modern seperti saat ini, media sosial meghapus batasan - batasan manusia untuk bersosialisasi, batasan ruang maupun waktu, dengan media sosial manusia dimungkinkan untuk berkomunikasi satu sama lain dimanapun mereka bereda dan kapanpun, tidak peduli seberapa jauh jarak mereka dan mereka memiliki perasaan yang nyaman menggunakan media sosial yang dapat kita bilang media baru ini. (Structures, n.d.)

Media sosial memiliki berbagai maanfaat yaitu ; sekedar untuk berkomunikasi dengan orang lain, untuk mencari tahu perkembangan sesuatu, untuk berbagi informasi maupun untuk mengikuti salah satu yang menjadi trend saat ini yaitu menggunakan media sosial sebagai bentuk eksistensi diri. Orang-orang yang hanya ingin menggunakan media sosial sebagai sarana menjaga silaturahmi biasanya akan memilih media sosial yang bersifat private saja seperti Line, Whatsapp, Path, Telegram, Messenger atau yang lainnya. Meskipun masuk ke media yang terbuka seperti Facebook, tiktok, dan Twitter maka mereka hanya akan menjadi penonton dan pembaca yang baik dan melihat perkembangan terbaru yang ada di media sosial. Sedangkan bagi orang-orang yang ingin diakui eksistensinya oleh masyarakat luas melalui media sosial biasanya akan menggunakan media sosial yang bersifat terbuka seperti Instagram, Facebook, Line, Twitter, dan tiktok yang baru baru ini buming. disinilah tempat kita bisa secara bebas dan terbuka dalam berinteraksi. Sehingga banyaknya update status serta posting-an yang kita miliki adalah salah satu bentuk jika kita ingin dikenal secara luas. Kita dikenal sebagai apa dan siapa itu kita yang memutuskan, karena apa yang kita posting melalui media sosial akan menjadi gambaran diri kita bagaimana kita memposisikan diri dimata masyarakat luas. (Wylęgała, 2010)

Perkembangan teknologi informasi dan komunikasi telah mengubah cara interaksi individu dengan individu yang lain. Jika dilihat pada zaman dulu manusia atau seseorang yang ingin menceritakan perasaannya membutuhkan orang lain untuk mendengarkan ceritanya tersebut, keadaan tersebut bergeser dengan hadirnya buku tempat menuliskan curahan hati atau perasaan yang dikenal sebagai buku diary. Sekarang masyarakat berada pada arus perubahan yang sangat cepat akibat media sosial. (Moos, 1984)

\section{TINJAUAN PUSTAKA}

Perkembangan bidang teknologi saat ini terjadi begitu pesat. Melalui perkembangan yang terjadi dari waktu ke waktu menimbulkan maraknya aplikasi - aplikasi serta platform media sosial yang bermunculan. Aplikasi yang sangat diminati oleh masyarakat saat ini diantaranya adalah TikTok, Instagram, Twitter, WhatsApp, Facebook dan yang lain sebagainya. Seiring berjalannya waktu, aplikasi sosial media tersebut dapat menjadi candu 
bagi kalangan masyarakat. Tidak hanya kalangan remaja yang menggunakan aplikasi sosial media, orang tua bahkan anak-anak juga aktif menggunakan aplikasi sosial media tersebut. Tiktok adalah sebuah aplikasi berbagi video yang memungkinkan pengguna mengambil Video, menerapkan filter digital, dan membagikannya ke berbagai layanan jejaring sosial. Sedangkan Tiktok adalah aplikasi gratis untuk berbagi video yang memungkinkan penggunanya untuk mengambil video dan selanjutnya berbagi pada layanan jejaringsosial. Tiktok banyak diminati semua kalangan tanpa terkecuali artis dari mancanegara, selebgram yang merupakan sebuah sebutan artis khusus di media sosial tiktok dan bahkan para pemilik online shop.

Tiktok yang semakin dirasakan memiliki kekuatan ataupun pengaruh dalam industri menimbulkan yaitu kualitas akun yang menentukan strata maupun kredibilitas pemilik akun.

\section{METODOLOGI PENELITIAN}

Maraknya penggunaan Tiktok menimbulkan fenomena baru yang dimanfaatkan perusahaan ataupun perorangan untuk berinteraksi maupun berkomunikasi. Kondisi ini dimanfaatkan untuk meraih pengikut (followers) dengan cara melakukan inovasi, pemasaran dan berkomunikasi secara online. Setidaknya ada 4 katagori pengguna tiktok yaitu :

1. Personal

2. Organisasi

3. Perusahaan

4. Pemerintah

Katagori Personal pada pengguna tiktok yang dimaksud contohnya adalah : Artis, Tokoh, Pejabat publik, Selebgram, pekerja profesional, dan lain sebagainya. Katagori Organisasi pada pengguna tiktok yang dimaksud contohnya adalah : Komunitas, Partai politik, NGO (Non-Governmental Organisation), NPO (nonprofit organization), dan lain sebagainya. Katagori Perusahaan pada pengguna instagram yang dimaksud adalah segala bentuk perusahaan yang bertujuan menghasilkan laba. Katagori Pemerintah pada pengguna instagram yang dimaksud adalah segala instansi pemerintahan sesuai dengan peraturan yang berlaku.

Penelitian ini menggunakan metode eksploratif kuantitatif untuk mengetahui kredibilitas dari performa akun tiktok 5 Brand Fashion termahal di dunia. Metode eksploratif merupakan penelitian yang memiliki tujuan untuk melakukan eksplorasi atau 
memperdalam pengetahuan ataupun ide-ide baru mengenai suatu hal yang baru, guna merumuskan permasalahan secara terperinci(“PENDEKATAN EKSPLORATIF UNTUK MENINGKATKAN KEMAMPUAN REPRESENTASI MATEMATIS DAN KEPERCAYAAN DIRI SISWA").

Tujuan dari penelitian ini yaitu mengetahui nilai kredibillitas dari performa tiktok 5 Brand Fashion Termahal Di Dunia. Ada beberapa langkah yang harus dilakukan dalam penelitian ini, sehingga mampu menemukan peringkat pertama akun tiktok 5 Brand Fashion Termahal Di Dunia yang memiliki performa terbaik. Langkah-langkah yang dilakukan pada penelitian ini, diantaranya yaitu :

\section{Melakukan Eksplorasi Pada Website Untuk Menentukan Objek yang Akan Dianalisa.}

Eksplorasi ini dilakukan pada beberapa halaman website yang menyediakan informasi mengenai objek yang akan di teliti. Setelah eksplorasi selesai dilakukan, sehingga ditemukan nama-nama vendor Brand Fashion Termahal Di Dunia yang akan dijadikan objek analisa. Setelah melakukan eksplorasi pada halaman website, maka langkah selanjutnya yaitu mencari nama akun Tiktok dari masing-masing vendor Brand Fashion Termahal Di Dunia. Pastikan semua vendor memiliki akun sosial media Tiktok.

\section{Menghitung Nilai Rata-Rata Variable Dari 5 Brand Fashion Termahal Di Dunia.}

Pada langkah ini, peneliti menghitung nilai variable Comment dan variable Like. Variabel penelitian adalah segala sesuatu yang berbentuk apa saja yang ditetapkan oleh peneliti untuk dipelajari sehingga diperoleh informasi, kemudian ditarik kesimpulannya.. Untuk menghitung nilai rata-rata dari variabel Comment dan variabel Like yaitu dengan cara mengambil minimal 10 postingan kemudian di hitung sehingga menemukan nilai rata-rata dari masing-masing variabel. 


\section{HASIL DAN PEMBAHASAN}

Akun Tiktok dari 5 Akun Tiktok, diantaranya :

1. Ralphlauren

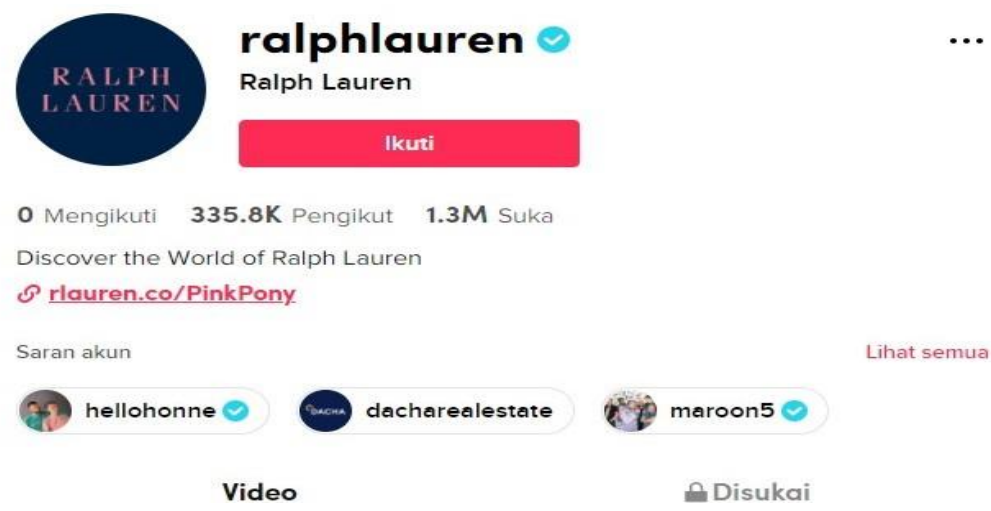

Gambar 1. Akun tiktok Ralphlauren

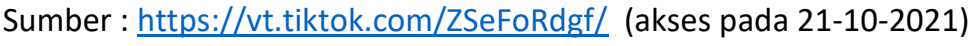

2. Dior

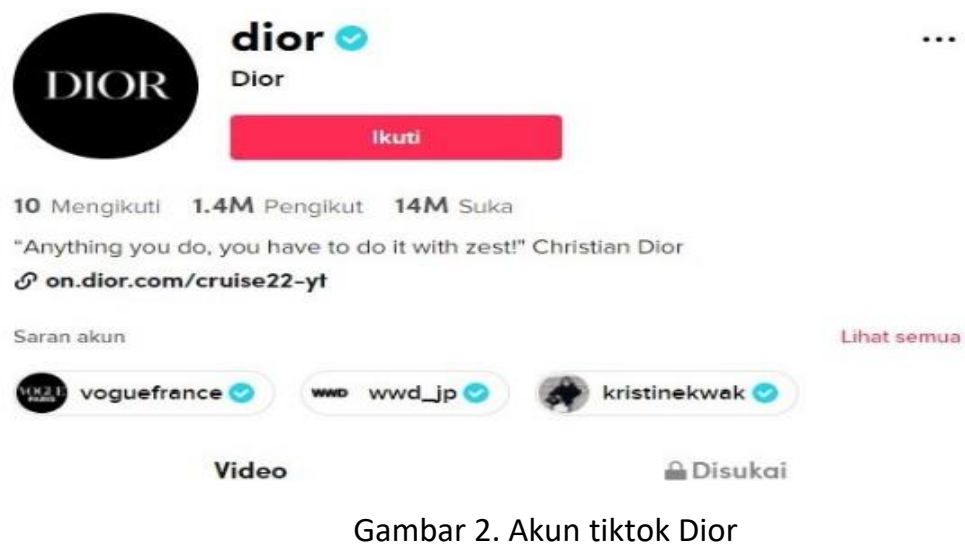

Sumber: https://vt.tiktok.com/ZSeFoj6tC/ (akses pada 21-10-2021) 
3. Armai Exchange

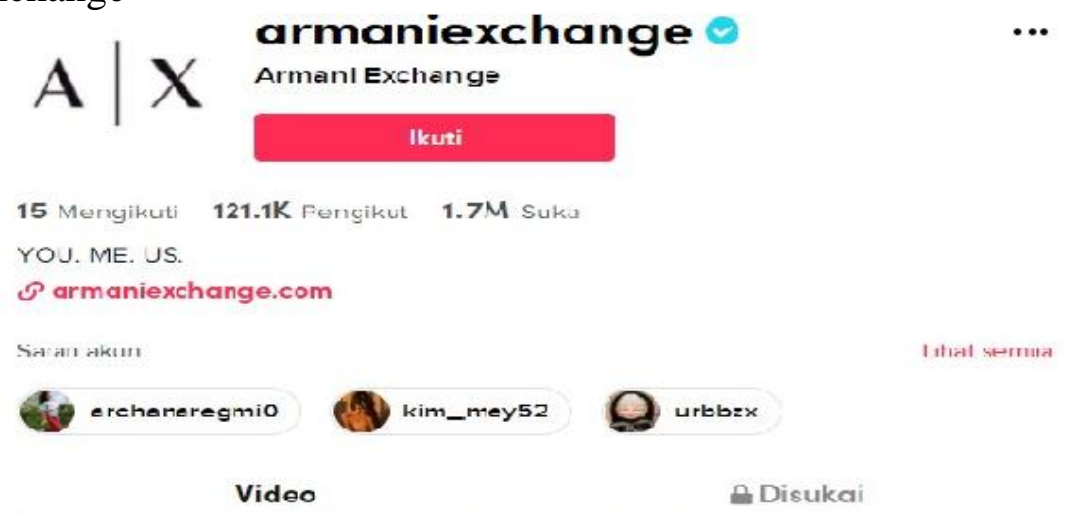

Gambar 3. Akun tiktok Armai Exchage

Sumber: https://vt.tiktok.com/ZSeFoURnK/ (akses pada 21-10-2021)

4. Versace

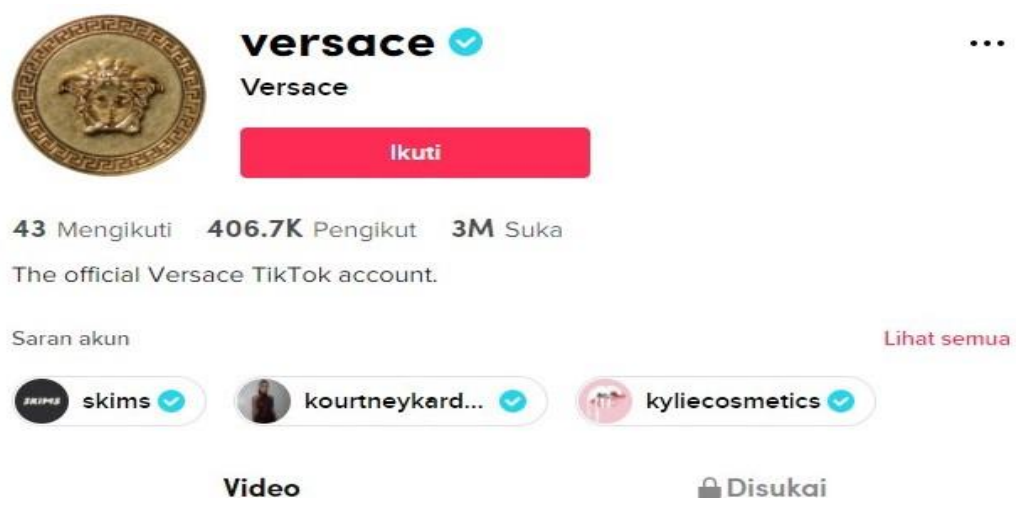

Gambar 4. Akun tiktok Versace

Sumber : https://vt.tiktok.com/ZSeFod4uw/ (akses pada 21-10-2021)

5. Fendi

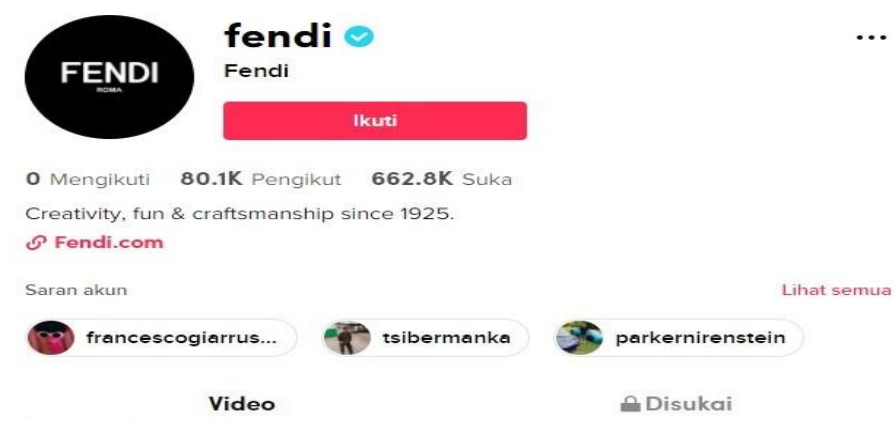

Gambar 5. Akun tiktok Fendi

Sumber : https://vt.tiktok.com/ZSeFodwpx/ (akses pada 21-10-2021)

Dari kelima akun tiktok 5 brand fashion di dunia dengan follower Terbanyak, peneliti menemukan nilai dari masing - masing variabel yang ada untuk menghitung rasio Video 
Comments to video like dari setiap akun. Pada akun tiktok terdapat 7 variabel, diantaranya yaitu :

1. Likes

2. Followers

3. Following

4. Video Likes

5. Video Comments

6. Video Share 7. Video Views

Dari ketujuh variabel tersebut peneliti hanya fokus untuk menemukan hasil dari 2 variabel, yaitu :

1. Video Comments

2. Video Like

Dari kedua variabel tersebut kemudian dianalisa sehingga menemukan nilai rata-rata dari variabel video comments dan variabel Video Like. Untuk menghitung nilai rata-rata dari variabel video comments dan variabel Video Like yaitu dengan cara mengambil minimal 10 postingan kemudian di hitung sehingga menemukan nilai rata-rata dari masing-masing variabel. Berikut merupakan tabel nilai rata-rata dari masing-masing Brand fashion di dunia dengan Follower Terbanyak, yaitu :

Tabel 1. Analisa Nilai Rata-Rata Nilai Variabel Video Comments dan Video LikeAkun Tiktok Ralph Lauren

\begin{tabular}{|} 
Ralph Lauren (@ ralphlauren) \\
\begin{tabular}{|c|c|c|}
\hline \multicolumn{3}{|c|}{ Ralph Lauren } \\
\hline No & Video Comment & Video Like \\
\hline $\mathbf{1}$ & 3 & 86 \\
$\mathbf{2}$ & 1 & 50 \\
$\mathbf{3}$ & 2 & 88 \\
$\mathbf{4}$ & 4 & 118 \\
$\mathbf{5}$ & 1 & 53 \\
$\mathbf{6}$ & 4 & 122 \\
$\mathbf{7}$ & 2 & 149 \\
$\mathbf{8}$ & 170 & 1 \\
$\mathbf{9}$ & 8 & 138 \\
$\mathbf{1 0}$ & 9 & 666 \\
\hline Total & 204 & 1471 \\
\hline
\end{tabular}
\end{tabular}

Sumber : Pengolah Data Excel 
Tabel 2. Analisa Nilai Rata-Rata Nilai Variabel Video Comments dan Video Like Akun Tiktok Dior

\begin{tabular}{|c|c|c|}
\multicolumn{3}{|c|}{ Dior(@dior) } \\
\hline \multicolumn{3}{|c|}{ Dior } \\
\hline No & Video Comment & Video Like \\
\hline $\mathbf{1}$ & 7527 & 586400 \\
$\mathbf{2}$ & 1802 & 99000 \\
$\mathbf{3}$ & 1055 & 57100 \\
$\mathbf{4}$ & 127 & 35900 \\
$\mathbf{5}$ & 42 & 2477 \\
$\mathbf{6}$ & 39 & 6492 \\
$\mathbf{7}$ & 39 & 3358 \\
$\mathbf{8}$ & 25 & 3771 \\
$\mathbf{9}$ & 20 & 2378 \\
$\mathbf{1 0}$ & 18 & 4766 \\
\hline Total & 10692 & 801642 \\
\hline
\end{tabular}

Sumber : Pengolah Data Excel

Tabel 3. Analisa Nilai Rata-Rata Nilai Variabel Video Comments dan Video Like Akun Tiktok Armani Exchange

\section{Armani Exchange (@armaniexchange)}

\begin{tabular}{|c|c|c|}
\hline \multicolumn{3}{|c|}{ Armani Exchange } \\
\hline No & Video Comment & Video Like \\
\hline $\mathbf{1}$ & 5 & 488 \\
$\mathbf{2}$ & 2 & 74 \\
$\mathbf{3}$ & 3 & 112 \\
$\mathbf{4}$ & 2 & 77 \\
$\mathbf{5}$ & 4 & 183 \\
$\mathbf{6}$ & 4 & 213 \\
$\mathbf{7}$ & 3 & 178 \\
$\mathbf{8}$ & 1 & 149 \\
$\mathbf{9}$ & 1 & 177 \\
$\mathbf{1 0}$ & 2 & 137 \\
\hline Total & 24 & 1788 \\
\hline
\end{tabular}

Sumber : Pengolah Data Excel 
Tabel 4. Analisa Nilai Rata-Rata Nilai Variabel Video Comments dan Video Like Akun Tiktok Versace

\begin{tabular}{|c|c|c|}
\multicolumn{3}{|c|}{ Versace (@versace) } \\
\hline \multicolumn{3}{|c|}{ Versace } \\
\hline No & Video Comment & Video Like \\
\hline $\mathbf{1}$ & 139 & 38900 \\
$\mathbf{2}$ & 63 & 14000 \\
$\mathbf{3}$ & 40 & 7423 \\
$\mathbf{4}$ & 65 & 8301 \\
$\mathbf{5}$ & 393 & 120000 \\
$\mathbf{6}$ & 56 & 7069 \\
$\mathbf{7}$ & 1847 & 36700 \\
$\mathbf{8}$ & 894 & 107000 \\
$\mathbf{9}$ & 109 & 35500 \\
$\mathbf{1 0}$ & 77 & 25700 \\
\hline Total & 3683 & 400593 \\
\hline
\end{tabular}

Sumber : Pengolah Data Excel

Tabel 4. Analisa Nilai Rata-Rata Nilai Variabel Video Comments dan Video Like Akun Tiktok Fendi

Fendi (@fendi)

\begin{tabular}{|c|c|c|}
\hline \multicolumn{3}{|c|}{ Fendi } \\
\hline No & Video Comment & Video Like \\
\hline $\mathbf{1}$ & 10 & 73000 \\
$\mathbf{2}$ & 2 & 204 \\
$\mathbf{3}$ & 7 & 148 \\
$\mathbf{4}$ & 24 & 122700 \\
$\mathbf{5}$ & 7 & 272000 \\
$\mathbf{6}$ & 3 & 289 \\
$\mathbf{7}$ & 2 & 288 \\
$\mathbf{8}$ & 5 & 184 \\
$\mathbf{9}$ & 45 & 1275 \\
$\mathbf{1 0}$ & 20 & 735 \\
\hline Total & 125 & 226020 \\
\hline
\end{tabular}

Sumber : Pengolah Data Excel 
Setelah menghitung nilai rata rata tersebut, maka akan menemukan hasil akhir nilai rata-rata dari variabel video comments dan variabel Video Like ratio

Tabel 6. Nilai Variabel Pada Akun Tiktok Brand Fashion Termahal di Dunia dengan Follower Terbanyak

Tabel Nilai Masing - Masing Variabel

\begin{tabular}{|c|c|c|c|c|c|}
\hline VARIABEL & FENDI & VERSACE & RALPH LAUREN & DIOR & ARMANI EXCHANGE \\
\hline Comment & 125 & 3.683 & 204 & 10.692 & 24 \\
\hline Like & 226.020 & 400.593 & 1.471 & 801.642 & 1.788 \\
\hline
\end{tabular}

Sumber : Pengolah Data Excel

Pada akun Tiktok terdapat 7 rasio yang relevan digunakan untuk mengukur kredibilitas pada masing-masing akun. Namun pada penelitian kali ini hanya berfokus untuk menghitung Video Comments to Video Like Ratio. Untuk menghitung kredibilitas dari masing-masing akun Tiktok setiap 5 Brand, peneliti menghitung dengan cara : variabel 1 akan dibagi dengan variabel 2, sehingga ditemukan hasil analisisa dari rasio tersebut. Tabel 7. Hasil Perhitungan Rasio Akun Tiktok

\begin{tabular}{|c|c|c|c|c|c|c}
\hline \multicolumn{7}{|c}{ TABEL RASIO } \\
\hline No & Ratio & Fendi & Versace & RALPH LAUREN & DIOR & $\begin{array}{c}\text { ARMANI } \\
\text { EXCHANGE }\end{array}$ \\
\hline 1 & $\begin{array}{c}\text { Video Comment To } \\
\text { Video Like Ratio }\end{array}$ & 0,000553048 & 0,00919387 & 0,138681169 & 0,013337625 & 0,013422819 \\
\hline
\end{tabular}

Sumber : Pengolah Data Excel

Video Comments to Video Like Ratio memiliki karakteristik yang tinggi, artinya semakin tinggi nilai yang dihasilkan maka semakin baik kredibilitas dari performa akun tersebut. Untuk memberikan peringkat pada masing-masing Brand, peneliti memberikan angka 5 kepada vendor yang mendapatkan nilai tertinggi dan angka 1 untuk vendor yang mendapatkan nilai terendah. Berikut merupakan tabel urutan nilai yang dihasilkan oleh masing - masing Brand. 
Tabel 8. Nilai Rasio Akun Tiktok 5 Brand di dunia dengan Followe Terbanyak

\begin{tabular}{|c|c|c|c|c|c|}
\hline \multicolumn{7}{|c|}{ Tabel Peringkat } \\
\hline Ratio & Ralph Lauren & Dior & $\begin{array}{c}\text { Armai } \\
\text { Exchange }\end{array}$ & Versace & Fendi \\
\hline $\begin{array}{c}\text { Video Comments } \\
\text { to Images } \\
\text { Comments }\end{array}$ & 5 & 4 & 3 & 2 & 1 \\
\hline
\end{tabular}

Sumber : Pengolah Data Excel

Dari Tabel Nilai Rasio 5 akun tiktok dengan Follower Terbanyak dapat simpulkan bahwa Ralph Lauren mendapatkan nilai tertinggi untuk rasio Video Comments to Video Like. Sedangkan akun tiktok Fendi mendapatkan nilai terendah untuk rasio ini. Jadi, pada penelitian ini Ralph Lauren memiliki kredibilitas performa yang lebih baik dibandingkan dengan akun tiktok lainnya.

\section{Kesimpulan}

Tujuan dari penelitian ini adalah mengetahui kredibilitas performa dari 5 akun tiktok dengan Follower Terbanyak menggunakan Video Comments to Video Like Ratio. 5 akun tiktok dengan Follower Terbanyak tersebut diantaranya : Larph Lauren, Dior, Armani Exchange, Versace, Fendi. Dari kelima Akun Tiktok tersebut dapat disimpulkan bahwa :

1. Peringkat pertama diraih oleh Ralph Lauren dengan nilai tertinggi yaitu 0,138681169

2. Peringkat kedua diraih oleh Dior dengan nilai yaitu 0,013337625

3. Peringkat ketiga diraih oleh Armani Exchange dengan nilai yaitu 0,013422819

4. Peringkat keempat diraih oleh Versace dengan nilai yaitu 0,00919387

5. Peringkat kelima diraih oleh Fendi dengan nilai yaitu 0,000553048 


\section{DAFTAR PUSTAKA}

M Moos. (1984). No Title Детская неврология. Ekp, 13(3), 576.

\section{PENDEKATAN EKSPLORATIF UNTUK MENINGKATKAN KEMAMPUAN} REPRESENTASI MATEMATIS DAN KEPERCAYAAN DIRI SISWA. (2016). Jurnal Pena Ilmiah, 1(1). https://doi.org/10.23819/pi.v1i1.2984

Putu, N., \& Ariyanti, D. (n.d.). Analisis Video Comments to Video Views Ratio Tiktok Pada Top 5 Vendor Smartphone di Indonesia.

Structures, M. B. (n.d.). No 主観的健康感を中心とした在宅高齢者における 健康関連指 標に関する共分散構造分析 Title. 1-9.

Zaida Victoria Narcisa Betancourth Aragón. (2010). No Title 7-1, ب بيبب بيبب. ئ ئ ئ ئئ ببيبب. https://repositorio.flacsoandes.edu.ec/bitstream/10469/2461/4/TFLACSO2010ZVNBA.p df 